\title{
Los desequilibrios regionales en España
}

\author{
Tomás Franco aliaga *
}

\begin{abstract}
\end{abstract}
Regional Inequalities in Spain

Regional inequialities have always existed as can be steen throughout Spanish Economic History. Until well into the Modern Age, inland Spain contained two thirds of the population and yielded most of the resources. However, the capitalist system and the free market exarcerbate such inequalities because of their own dynamics, polarizing resources in order to obtain the highest profit.

The consequences of this, seen from the geographical point of view, are a migrant population, environmental changes, urban growth, and the adoption of new forms of spatial organization, among others.

Between 1960-1973 the country witnessed a "miraculous" economic growth rate and as such there was a widespread and significant backward movement with important effects in the more industrially developed regions. The economic recovery (1986-1989) maintains such inequalities although the development axes spread in a "4" form which embraces the Valle del Ebro (Ebro Valley), the mediterranean arch from Gerona (Nort Cataluña) to Málaga (South-East Andalucia) and both archipielagos and

\footnotetext{
* Departamento de Geografía. UNED.
} 
Madrid, which still is the well established reference point in present-day Spain and its autonomous regions.

\section{LOS DESEQUILIBRIOS INEVITABLES}

De la misma manera que siempre habrá pobres entre nosotros, en un evangelio capitalista, la presencia de los desequilibrios regionales parece una realidad social y económica ineludible. Martínez Cortiña (1990, 77) lo dice con la precisión del especialista: "Cuando el sistema político económico vigente es el capitalista, como es el caso de España (...) se produce una tendencia «natural» a la concentración y polarización de la actividad económica, tanto desde el punto de vista funcional y sectorial como en la distribución espacial».

Nos hallamos, pues, ante una más de las muchas realidades que fluyen fatalmente del manantial del sistema, que a una parte reverdece y a otra elude y se agosta. $Y$ esto siempre ha sido asi y y seguirá siéndolo.

Algunos piensan, adentrándose por los caminos de la lógica, que "el desequilibrio regional se da cuando es perceptible la mayor eficacia del sistema económico en una región respecto de otra" (Higueras, 1980, 229). Está claro que cualquier fenómeno, para su comprensión, ha de conformarse en el molde la relatividad, de la relación, porque encerrado en sí mismo ni siquiera existe; pero las dificultades en el análisis aparecen cuando pretendemos cribar el grano de la paja, hallar los orígenes, las causas, los niveles, las consecuencias y las posibles soluciones a tales desequilibrios.

Para Higueras está claro que "los desequilibrios regionales no provienen tanto de la diversidad de actividades econonómicas, ni de las peculiaridades del medio físico, cuanto de los medios con que el sistema económico potencia determinadas formas de actividad, que obviamente tienen una ubicación espacial concreta, de acuerdo con los esquemas de sus propios intereses" (pág. 233). El desequilibrio es el resultado de una actitud "de quienes están capacitados o legitimados para tomar decisiones" (pág. 232).

Adscrito explícitamente a "la tesis posibilista", Higueras entiende que los desequilibrios son fruto de una decisión concreta y puntual, pues algunas regiones se benefician de una «inversión polarizada", buscando una mayor rentabilidad, a costa del resto. De ahí que no sea partidario de hablar de "desequilibrios" como algo estructural o permanente, sino 
de "desigualdades", que éstas sí son «inherentes a la propia esencia del espacio regional».

De la mano de la coherencia, entiendo que las "desigualdades" carecen de interés para un análisis de la dinámica social porque, como realidades inertes - el relieve, la climatología, etc. - siempre han estado y seguirán estando ahí. Sin embargo, el fluir de la economía, como un río, fertiliza amplias regiones mientras otras quedan marginales y baldías. Parafraseando el dicho, las desigualdades nacen, los desequilibrios se hacen. De ahi el interés de estos últimos por conyunturales y porque aún nos queda la leve esperanza de poder atemperarlos.

\section{BREVE MEMORIA HISTORICA DE LOS DESEQUILIBRIOS REGIONALES}

En cualquier actividad reflejamos nuestras manías más intimas y una de las mías es lanzar el sedal de la memoria al pasado buscando un mayor recorrido para la comprensión de los fenómenos. Un breve repaso por la historia de los desequilibrios regionales puede facilitarnos y enriquecer su conocimiento actual.

Siguiendo a Álvarez Llano (1986), a principios del siglo xIV la mayor parte de la población española vive en la Meseta $y$, dentro de ésta, preferentemente en la zona norte. A finales del siglo XVI hay un desplazamiento poblacional y económico hacia el sur. Pero el interior peninsular sigue siendo el espacio más rentable y el que mayores cargas fiscales soporta, pues las tierras castellanas contribuyen con un 52,7 por 100 (Cuadro 1).

El siglo XVII supone ya un retroceso para las tierras del interior. Castilla se despuebla por la emigración de los campesinos hacia las ciudades y colonias y por las levas, el hambre y las enfermedades. Si en 1591 las provincias interiores albergaban el 56,4 por 100 de la población, en 17121717 el porcentaje había descendido al 43 por 100 y al 38,8 por 100 finalizando la centuria.

Durante el siglo XIX la industrialización acelera el trasvase de la gente hacia la periferia. Cuatro siglos más tarde, aquel contundente 56,4 por 100 se ha convertido en un 30,2 por 100 y si exceptuamos Madrid, cuyo desarrollo aún desequilibra más el entorno, la población se reduce a un 17,7 por 100 del total del país. Pero el Cuadro 1 ofrece todavía muchas más posibilidades de análisis, pues nos permite seguir el pro- 


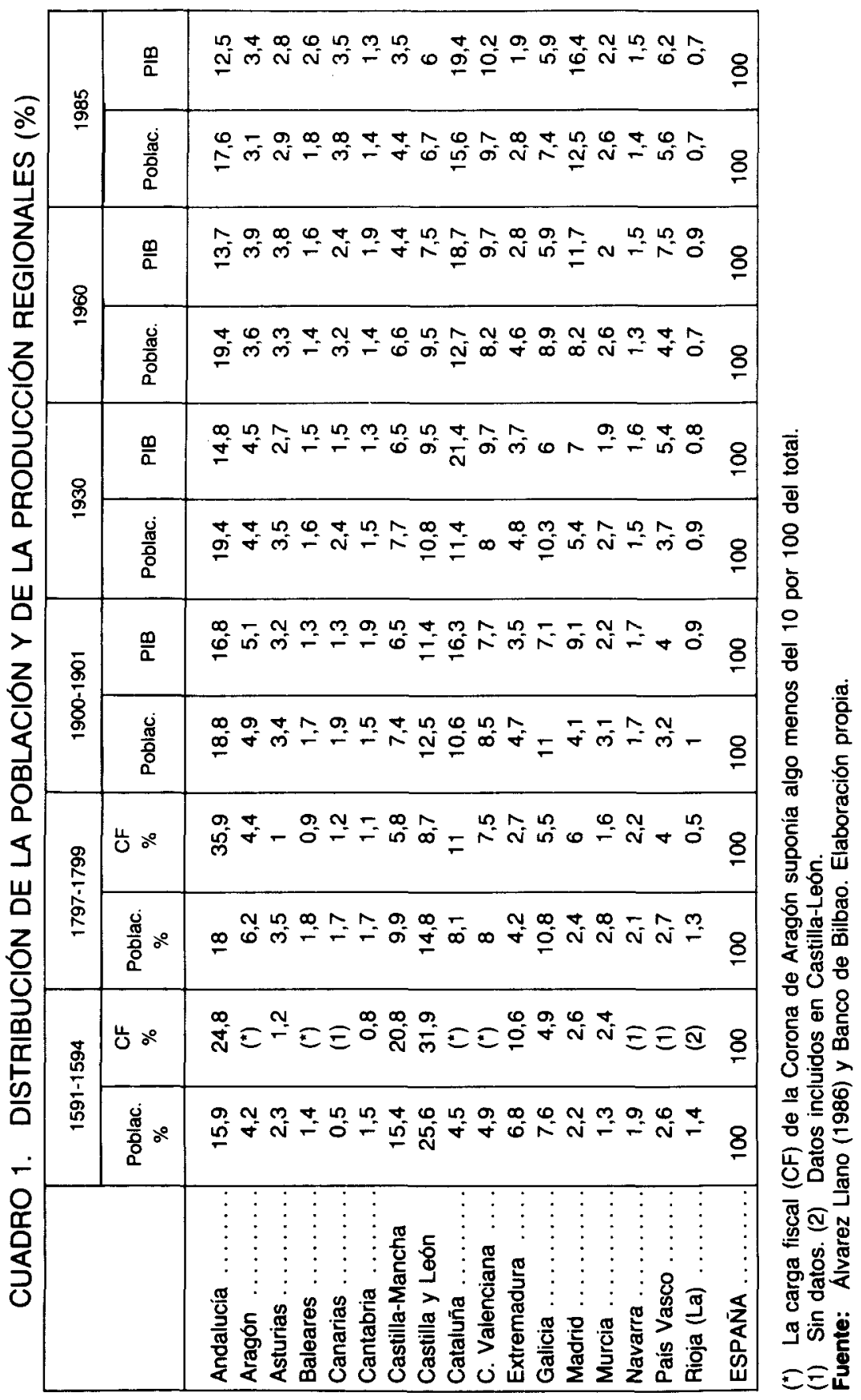


ceso evolutivo del resto de las regiones, tanto desde el punto de vista demográfico como del económico.

La carga fiscal de ambas Castillas y Extremadura, lo que a grandes rasgos nos aproxima a su potencial económico, se reduce en estos 400 años a una sexta o a una quinta parte y la de Andalucía, justo a la mitad. Por el contrario Cataluña, la comunidad Valenciana y los dos archipiélagos multiplican su importancia económica por tres y Madrid por seis.

Quizá parezcan naturales estos vaivenes teniendo en cuenta el largo tiempo transcurrido y los muchos cambios de que hemos sido testigos en los últimos decenios de nuestra historia. Pero, nada menos, es el Ministerio de Hacienda, demiurgo de la economía, el que asegura en un informe reciente (1990) que "como resultado de la dinámica histórica, se observa una concentración geográfica de la población, de la producción y del empleo tan intensa como quizá no se produzca en ningún otro Estado de la CEE" (pág. 23). Que tomen nota los que coleccionan perlas sobre nuestras peculiaridades.

El análisis de estos tres elementos señalados, población, producción y empleo, nos permite una visión global de los desequilibrios regionales, antes de adentrarnos en el análisis del desarrollo económico desde 1950 a 1983 .

a) "La densidad demográfica" es un factor meramente cuantitativo, pero que se torna cualitativo a partir de un cierto umbral siempre difuso. La densidad española por $\mathrm{km}^{2}$ es de 75,6 habitantes (1985), pero las disparidades van desde los 21 y 25 habitantes $/ \mathrm{km}^{2}$ de Castilla-La Mancha y Aragón, respectivamente, a los 597 de Madrid o los 295 del País Vasco. En medio hay una gran variedad de situaciones, pero queda claro que el desarrollo a partir de los años 60 surge y se consolida en regiones cuya densidad supera la media nacional, salvo Navarra y Aragón, cuya posición estratégica compensa con creces esta cárcava demográfica. Si descendemos al nivel provincial, los desequilibrios son abrumadores: entre 9 y 13 habitantes por $\mathrm{km}^{2}$ en Soria, Teruel, Guadalajara, Cuenca y Huesca y los casi 600 de Barcelona y Madrid, con 13 provincias más por encima de los 100 y todas ellas periféricas, con salida al mar.

Los factores de natalidad y mortalidad han tenido cierta incidencia, pero han sido los movimientos migratorios los que, a partir de los años cincuenta, han rastrillado vigorosamente la población interior amontonándola sobre la costa.

b) “El producto interior bruto" (PIB) por habitante, la "renta "per cápita" y la "renta familiar "per cápita"» son otros tantos aspectos de 
tipo económico que repiten el esquema anterior. En todos ellos las mismas regiones, con alguna ligera variante, se sitúan por encima de la media nacional marcando netas diferencias con el resto. Así, Extremadura, Andalucia y Castilla-La Mancha tienen una renta "per cápita" del 65,3 por $100,71,4$ por 100 y 74,9 por 100 , respectivamente, sobre la media nacional, porcentajes que se reducen al 41,1 por $100,44,9$ por 100 y 47,1 por 100 si los comparamos con las Baleares (Fies, 1990). Pero de la incidencia del desarrollo económico sobre los desequilibrios regionales hablaremos luego con mayor detalle.

c) "El empleo y el paro", "Los desequilibrios regionales en el empleo y en mercado laboral presentan características extremadamente graves, no sólo en aquellas Comunidades que han visto cercenada su tradicional solución en la emigración, sino también en otras urbano-industriales, seriamente afectadas por la crisis reciente" (Alonso, 1990, 76).

Suele tomarse como un índice sólido del desarrollo el de la ocupación sectorial de la mano de obra (Giráldez, 1988, 267). Y así, cuando ésta se concentra preferentemente en los servicios y en la industria, por ese orden, se entiende que disfruta de un nivel de vida medio o elevado. Por el contrario, la "agrarización" de la población activa significa minifundismo, predominio de los modos tradicionales sobre las leyes del mercado y escasa mecanización.

La estructura por sectores en España (1985) era la siguiente: Agricultura y Pesca (16,5 por 100), Industria y Construcción (31 por 100) y Servicios (52,2 por 100). Diez de la CC.AA superan el porcentaje medio agrario y algunas, con cifras desalentadoras: Galicia (43 por 100), Extremadura (31,6 por 100), Castilla-La Mancha (27,9 por 100), Castilla y León $(26,9$ por 100$)$ y Cantabria $(23,0$ por 100$)$.

Pero con ser grave la situación de estas regiones, por hallarse muy alejadas de las exigencias que entraña el desarrollo económico, aún es más precupante cuando descendemos al infierno del desempleo. En un sistema socieoeconómico donde el trabajo es la llave de una existencia digna, un derecho constitucional y un mandato divino, carecer del mismo significa ser arrojado, de una u otra manera, fuera del recinto, extramuros.

$Y$ en este caso, los desequilibrios no se reparten por regiones, sino que, paradójicamente, las mayores "sacas" (que ya no "bolsas») de desempleo se dan en las zonas más industrializadas, donde la crisis (1973-1985) ha incidido con especial virulencia. 


\section{LA ETAPA DEL DESARROLLO (1960-1973)}

\section{a) Sistole y diástole}

Cualquier cambio en un colectivo, salvo por incidentes traumáticos, es el resultado de un proceso y así se entiende la idea de desarrollo. Sin contradecir lo anterior, hay sin embargo en la España de la postguerra una fecha-bisagra mágica, el año 1959, nacimiento del Plan de Estabilización. En lo económico se abandona la autarquia y en lo moral se acortan las faldas y se alarga la tolerancia. Socialmente se fragmenta "la unidad de destino" y políticamente cambian los collares, con lo que los mismos perros van pareciéndonos distintos.

Las fronteras se hacen permeables para los créditos, la tecnología y, más lentamente, también para las ideas liberales que circulan por Europa.

Desarrollo implica división del trabajo o especialización, mayor productividad y transformación de una economía tradicional agrícola en industrial y de servicios. A veces, incluso, trae debajo del brazo, como un pan bendito, la democracia. No fue nuestro caso.

Para Racionero (1987), el motor del desarrollo es la información que empapa la sociedad donde se generan cambios que trascienden la tecnologia y devienen en culturales.

Un geógrafo, para ceñirse a la topografía, debe cartografiar estos fenómenos y analizar sus repercusiones espaciales. Para él, desarrollo significa movimientos de población, campos abandonados, transformación del terrazgo, mecanización agraria, crecimiento de las ciudades, chabolismo, espacios industrializados, densidad de la red viaria, contaminación, tiempo de ocio, etc.

Todo este proceso gira en torno a un eje, la ciudad. En ella es donde más se acumula y mejor se difunde la información. Y esta concentración urbana, y por tanto espacial, es la base de los desequilibrios regionales en la década de los sesenta. Las ciudades succionan las energias de su entorno y acaparan las mayores cotas de desarrollo. Este, en sus inicios, agudiza las desigualdades y enerva los desequilibrios. Polarización máxima con una dispersión reducida al mínimo. Pocas regiones producen y el resto compra. $Y$ todo va sucediendo en cascada: de las grandes ciudades a las pequeñas, de las regiones desarrolladas a las de nivel inferior. 
Racionero tiene claro que siempre es preferible una economía dual a un retraso generalizado, o sea, que ve los desequilibrios como un mal menor.

El movimiento del corazón puede servirnos como ejemplo del proceso: en la primera fase o "sístole" varias regiones acaparan el grueso del caudal energético vaciando las extremidades; en la segunda o diástole el resto del organismo se beneficia del impulso centrífugo.

Como teoría-metáfora tiene cierta validez. En la práctica, siempre aparece algún trombo hacia la periferia, claro está. Los Polos de desarrollo son un buen ejemplo: cumplieron a la perfección la primera fase o sístole succionando las mejores energías del territorio próximo (Bielza, 1985), pero fracasaron en el impulso posterior. Y aquí, a diferencia del corazón, no se genera un colapso fatal para el organismo sino el deterioro azulado o la gangrena para las extremidades.

El análisis de los desequilibrios regionales debe adoptar una unidad básica de referencia. En nuestro caso va a ser la comunidad autónoma, territorio en algunos casos tan amplio como para albergar en su interior desequilibrios tanto o más profundos que los interregionales. Lo ideal sería llevar la lupa, no ya provincia a provincia sino por los desequilibrios comarcales "que son, sin duda, lo más interesantes a la hora de intentar corregirlos" (Casas, 1968, 31). Por falta de posibilidades para esto último, nos volveremos al plano "autonómico".

\section{b) El impacto del desarrollo}

Superado el trauma de la Estabilización, la economía española se beneficia de dos circunstancias excepcionales: su "apertura" al exterior, donde las economías occidentales se hallan en pleno desarrollo, y la “liberalización" del mercado interior. Ello supuso eliminar "algunas de las rigideces existentes y el clima intervencionista dominante lo que facilitó la movilidad espacial de los factores y una clara mejora en la asignación de los recursos" (Cuadrado, 1988, 20).

Entra en crisis la agricultura tradicional, crece el sector secundario y los servicios pasan a encabezar definitivamente la participación en el PIB. Esto supone una fuerte convulsión para algunos subsectores industriales (alimentación, minería y textil) y el despegue en vertical de otros (metálicas básicas y de transformación, papel, artes gráficas y edición y la construcción). La agricultura se ve forzada a mecanizar sus labores, a entrar de lleno en una economía de mercado y a prescindir masivamente de su mano de obra más joven y emprendedora, que recala en la industria o 
en los servicios urbanos, como etapa intermedia en muchos casos, antes de partir hacia Europa.

Como resultado de todo ello, aparece el primer gran impulso centripeto, la "sístole" de que hablábamos más arriba, y tanto la producción como el empleo se concentran en las CCAA de Baleares, Canarias, Cataluña, Madrid y, en menor medida, en la Comunidad Valenciana y en el País Vasco. Murcia, Navarra y La Rioja mantienen su aportación al VAB en porcentajes similares a lo largo del período (1960-1973) y en resto pierde ritmo en mayor o menor medida. EI VAB de las seis CCAA con crecimiento positivo pasa de ser el 51,6 por 100 del total en 1960 al 57,5 por 100 en 1973 y el empleo, del 38,6 por 100 al 47 por 100 .

Esta concentración o polarización de la economía, no significa que el resto del país no crezca, sino que lo hace a un ritmo más lento. De hecho, la media anual alcanza el 7,4 por 100 acumulado, situación insólita o "milagrosa», para adecuar el lenguaje al ambiente teocrático del momento.

En el cuadro n. 2 aparece la distribución de la producción y del empleo. En él se evidencian los desequilibrios apuntados, pero si, a través de los datos del Banco de Bilbao, analizamos una a una la situación provincial, las diferencias sorprenden dolorosamente pues, Lugo (3,55 por 100) Zamora (3,56 por 100$)$, Badajoz (3,78 por 100) y Jaén $(3,86$ por $100)$ se quedan a siete puntos de Álava $(10,73$ por 100) o Baleares $(10,66$ por 100$)$ y entre cuatro y seis de las provincias del ámbito mediterráneo.

Finalmente, el desarrollo de algunas áreas se produce por la "expansión metropolitana" de los grandes núcleos industriales hacia su entorno más próximo, (tal es el caso de Barcelona hacia Gerona y Tarragona, de Bilbao hacia Burgos y Álava y de Madrid hacia Guadalajara y Toledo); por el «impulso oficial» a través de los Polos de Desarrollo y por la "industrialización local endógena" "uno de los puntales básicos de la estructura industrial de importantes áreas de industrialización intermedia (Alicante, Gerona, Castellón, Baleares, Navarra, Rioja) y de débil industrialización Jaén, Albacete, Murcia, Burgos, Toledo, Badajoz, Ciudad Real y Córdoba), lo que le confiere un papel estratégico en la estructura productiva" (Vázquez, 1986, 103).

\section{c) La especialización sectorial}

Una de las caracteristicas que definen la etapa del desarrolio es la fuerte tendencia de las regiones hacia la especialización. Los subsectores 
CUADRO II. TASAS MEDIAS DE CRECIMIENTO ANUAL DEL PIB $(1960-1973$ y 1985$)$

\begin{tabular}{|c|c|c|c|}
\hline COMUNIDADES AUTONOMAS & 1960 & $1973-85$ & 1985 \\
\hline Andalucia .. & 6,7 & 2,3 & 1,5 \\
\hline Aragón $\ldots \ldots \ldots \ldots \ldots \ldots \ldots \ldots$ & 6,3 & 2,6 & 1,8 \\
\hline Asturias $\ldots \ldots \ldots \ldots \ldots \ldots \ldots$ & 6,2 & 1,0 & 0,3 \\
\hline Baleares $\ldots \ldots \ldots \ldots \ldots \ldots$ & 10,6 & 3,1 & 4,1 \\
\hline Canarias $\ldots .$. & 9,8 & 3,4 & 2,3 \\
\hline Cantabria ...... & 5,1 & 1,7 & 0,8 \\
\hline Castilla-La Mancha ... & 6,2 & 1,4 & 1,1 \\
\hline Castilla y León...$\ldots \ldots$. & 5,8 & 2,2 & 1,3 \\
\hline Cataluña $\ldots \ldots \ldots \ldots \ldots \ldots \ldots$ & 8 & 2,2 & 0,7 \\
\hline Comunidad Valenciana ...... & 7,3 & 2,9 & 2,0 \\
\hline Extremadura $\ldots \ldots \ldots$ & 4,2 & 2,2 & 2,3 \\
\hline Galicia $\ldots \ldots \ldots \ldots \ldots$ & 6,7 & 3,1 & 1,4 \\
\hline Madrid $\ldots \ldots \ldots \ldots \ldots \ldots \ldots \ldots$ & 9,3 & 3,4 & 1,3 \\
\hline Murcia $\ldots \ldots \ldots \ldots \ldots \ldots$ & 7,6 & 3,0 & 2,0 \\
\hline Navarra ....... & 7,2 & 2,2 & 1,7 \\
\hline País Vasco $\ldots . . . \ldots \ldots \ldots \ldots \ldots$ & 7,5 & 0,7 & 0,6 \\
\hline Rioja (La) $\ldots \ldots \ldots \ldots \ldots \ldots \ldots$ & 5,7 & 2,8 & 1,6 \\
\hline Total España $\ldots \ldots \ldots \ldots \ldots$ & 7,40 & 2,4 & 1,4 \\
\hline
\end{tabular}

Fuente: Banco de Bilbao. Renta nacional de España.

industriales más favorecidos son las industrias metálicas de transformación y la química, quedando relegadas a la alimentación, minería y textil, tan decisivas en todo el período anterior hasta el despegue industrial (Mancha, 1984, 42).

Existen numerosos estudios sobre la especialización industrial por subsectores y por provincias, pero mi intención es dar una visión más amplia, aunque se diluyan los matices. De ahí que el índice del Cuadro 3 se haya elaborado desde el nivel sectorial partiendo de la siguiente fórmula: se divide el porcentaje sectorial de cada CA por la media nacional del sector. Si el cociente supera o no la unidad, indicará el grado positivo o negativo de especialización regional con respecto a la media del país.

El siguiente gráfico, elaborado a partir de los datos del Cuadro 3 , permite una visión instantánea del índice de especialización por sectores de cada Comunidad Autónoma.

La especialización en el sector primario parece un nada envidiable patrimonio de la España interior. Hay algunas CCAA cuyo índice queda 


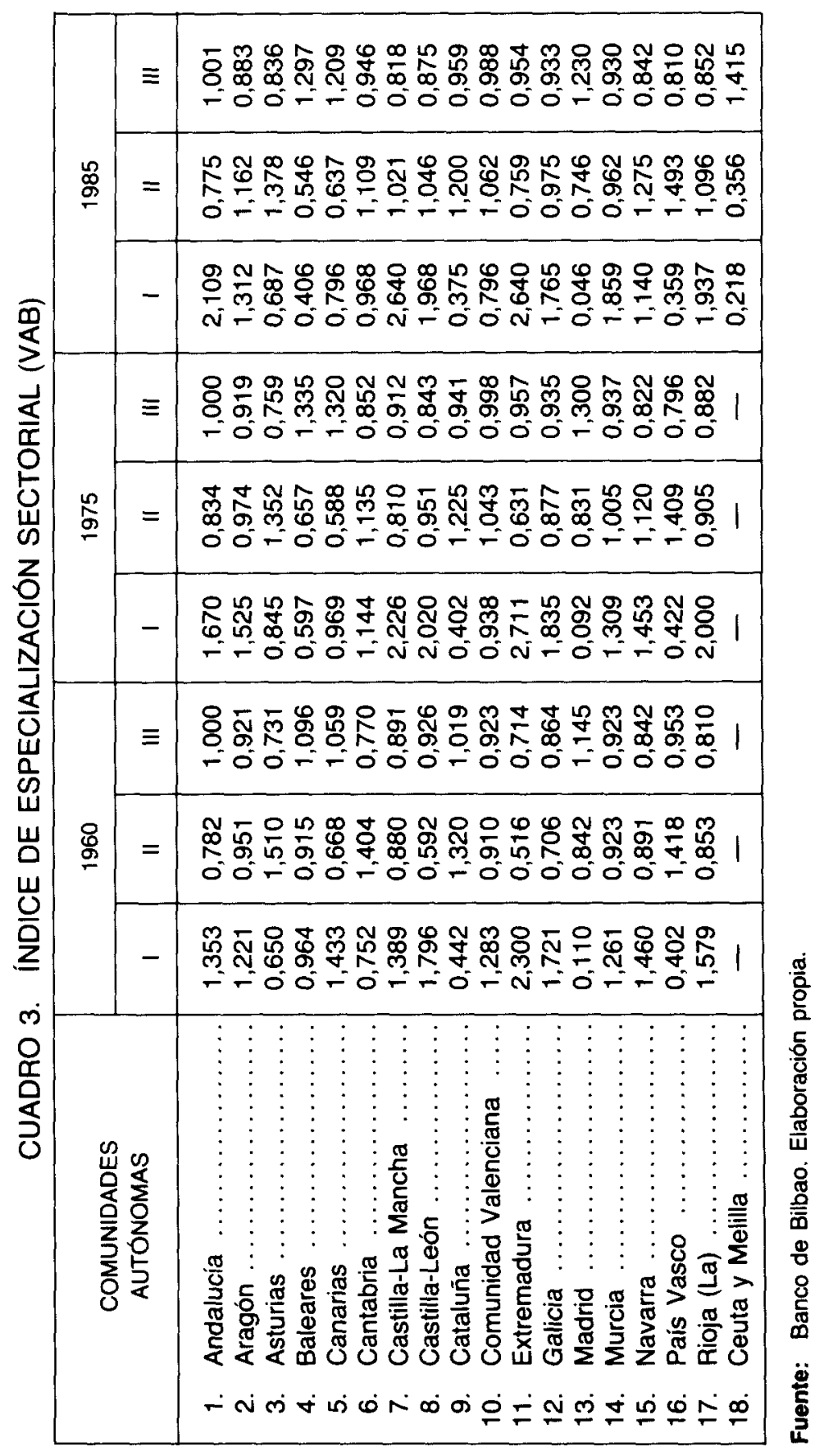


TOMÁS FRANCO ALIAGA

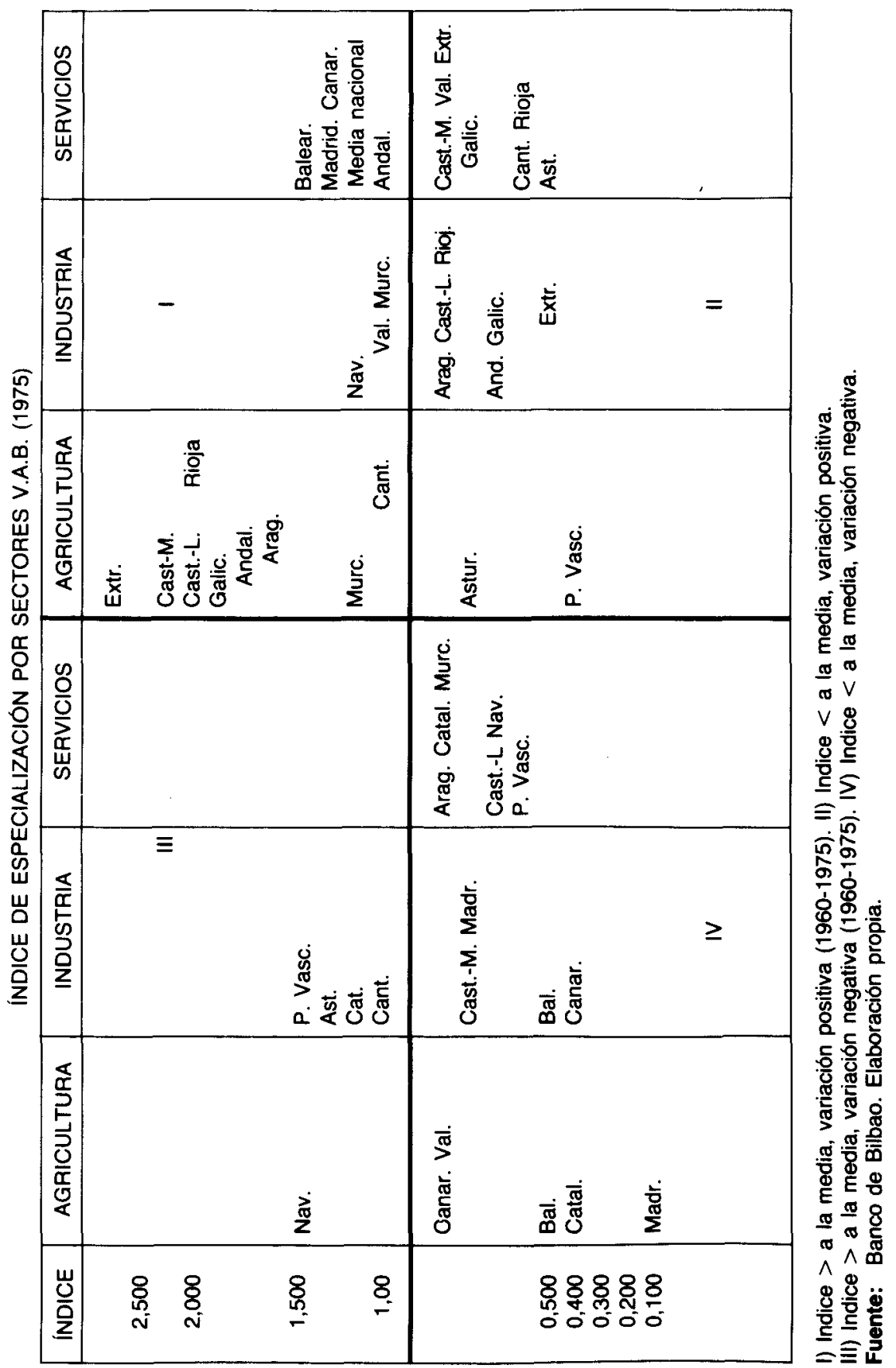


muy por debajo de la media (IV). Ello se debe, especialmente, al fuerte desarrollo de los servicios (Madrid), ligado al turismo (Baleares y Canarias).

Si para un economista esta etapa de desarrollo supone un caudal inagotable de análisis y estudio, no lo es menos para un geógrafo, como se insinuaba más arriba. Como simple esbozo voy a enumerar algunos aspectos determinantes en la configuración de los desequilibrios regionales.

1. Desde las zonas rurales del interior "se pone en marcha un poderoso flujo humano" que culmina las tendencias ya iniciadas en el siglo XVIII. El trasvase fue de tal magnitud que varios millones de personas cambiaron de residencia en ese período trastocando la densidad demográfica y las pirámides de población de todas las regiones.

2. «El paisaje rural cambia de aspecto», no sólo por la aparición de los nuevos cultivos que demanda una agricultura de mercado, sino por el abandono de innumerables parcelas, escasamente rentables o sin brazos jóvenes para cultivarlas.

3. "Las ciudades aceleran su desarrollo" para dar acogida a este río humano sin control. Tomadas por sorpresa, crecen sin una verdadera planificación, siendo víctimas de especuladores, chapuceros y espontáneos.

4. "Muchas industrias quedan atrapadas" entre los nuevos barrios obreros, repitiendo imágenes de la Europa fabril del XIX.

5. "La red viaria cambia a duras penas" la epidermis asfáltica, pero sin ampliar sus capacidades ni su trazado.

6. "Los nuevos ciudadanos se apiñan" en pisitos minúsculos, abandonan en parte viejas creencias y tradiciones anatematizados por los guardianes oficiales del orden anterior, trabajan y consumen infatigablemente y sientan las bases de la décima potencia industrial.

Este largo decenio de desarrollo se caracteriza por el "rebose" industrial de los centros consolidados hacia su entorno, más o menos próximo, a través de ejes bien comunicados. Es cierto que se consigue «una creciente integración del sistema industrial español, contribuyendo de paso a reforzar los desequilibrios interterritoriales". Pero "los efectos derivados de la política regional, tanto en la orientación del proceso difusor como en la moderación de las desigualdades a través de la promoción industrial en áreas deprimidas, pueden calificarse de modestos y puntuales, no llegando a modificar de forma demasiado significativa las tenden- 
cias «espontáneas», coherentes con la lógica del mercado» (Méndez, 1990, 124).

\section{LA CRISIS ECONÓMICA (1973-1985)}

Internacionalmente se da el año 1973, estallido del precio de los crudos, como fecha-gozne sobre la que el desarrollo anterior gira y se derrumba. En España, se dice que por la transición política, -especie de contrarreforma en lo económico-, la crisis se retrasa oficialmente varios años. Cuando se quieren tomar medidas, la economía está con un pie en el aire $y$ el otro sin apoyo. Se han perdido varios años de crucial importancia.

Los aspectos más destacables de la crisis son: una caída del índice de crecimiento, la desaparición de innumerables empresas, el crecimiento incontenible del paro, el freno de las emigraciones, el mantenimiento de los equilibrios, la consolidación de un nuevo eje de desarrollo regional y la política de reconversión industrial.

\section{A) Caida del índice de crecimiento}

El crecimiento medio de la etapa anterior $(7,4$ por 100$)$ se reduce drásticamente $(2,4$ por 100$)$, afectando sobre todo a la industria y a la construcción y algo menos a la agricultura y a los servicios.

Observando las tasas de crecimiento para este período (Cuadro 2), varias regiones consolidan el desarrollo de la etapa anterior (Baleares, Canarias, Madrid y Murcia) y otras mantienen su despegue por encima de la media nacional (Aragón, Comunidad Valenciana, Galicia y La Rioja). El resto queda por debajo de la citada media, destacando el hundimiento del País Vasco, Asturias y Cantabria o la persistencia en el subdesarrollo de ambas Castillas, así como el encono con que se cebó la crisis en el tejido industrial barcelonés.

\section{B) Desaparición de numerosas empresas}

Este terremoto empresarial hunde sus raíces en un magma palpitante y difuso del período anterior. Muchas industrias habian surgido con una dimensión y organización indadecuadas, sin previsiones de financiación a medio o largo plazo e incapaces de competir ventajosamente con 
los productos del exterior en una economía abierta. Se habian creado miles de industrias porque una demanda insaciable de productos, tras décadas de privaciones, engullía de inmediato cualquier oferta. A veces, incluso, precedía la cartera de pedidos a la creación de la industria. Sirva como ejemplo de esta "presunta" exageración el sistema muchas veces utilizado para la construcción de viviendas: en el solar elegido aparecía un cartel sobre características del proyecto y formas de pago. Las más de las veces éstas exigian una parte sustancial del precio antes de haberse iniciado las obras.

\section{C) Crecimiento del paro}

La crisis en Europa cierra las puertas a nuestros emigrantes e incluso fuerza su regreso. En el interior, la industria y, en menor grado, la agricultura y los servicios crean un desempleo continuo que se engrosa con la llegada al mercado del trabajo de las nuevas generaciones, fruto de los acelerones del desarrollo. Pero a estas razones hay que añadir las «ligadas al funcionamiento del sistema, a las actitudes dominantes del mercado de trabajo y al propio retraso en el proceso de ajuste provocado por la crisis" (Cuadrado, 1988, 31).

\section{D) Freno migratorio}

Ya se ha insinuado en el punto anterior la grave incidencia que tuvo en el paro la caída de la demanda laboral europea y el paulatino regreso de los cientos de miles que partieron en la etapa desarrollista. $Y$ aún se enconó más el desempleo por la demanda laboral femenina y la estabilización de los movimientos migratorios en el interior. Esto último supuso el enquistamiento de bolsas locales de paro al perderse la fluidez anterior del mercado laboral.

\section{E) Mantenimiento de los desequilibrios regionales}

Si volvemos al Cuadro 2, podemos afirmar que la crisis afectó a todas las regiones españolas aunque de manera muy desigual, entre otros motivos, porque no todas partían en igualdad de condiciones ni poseían la misma capacidad de reacción ni les favorecía un sistema adecuado de comunicaciones ni se hallaban próximas a los ejes favorables del desarrollo. Desde las esferas oficiales, según Cuadrado (1988), ha perdido peso específico la política regional, que nunca ha tenido un di- 
seño claro, porque las soluciones urgían planteamientos de carácter macroeconómico, globales o sectoriales, más que de ámbito espacial.

Cuando surgen reticencias, se crean las ZUR para atemperarlas, pero más como un parche que como una solución integrada. Por otro lado, hay una cierta "desconfianza en la planificación económica - soporte de los programas regionales- y en la eficacia de los incentivos, uno de los instrumentos tradicionales de la política regional" (Cuadrado, 1988, 32).

\section{F) Consolidación de un nuevo eje de desarrollo regional}

Este "nuevo" eje lo es tan sólo en parte, pues engloba algunas regiones de antaño con otros de reciente incorporación. Arranca en el valle del Ebro, desde Álava y continúa por Navarra, La Rioja y Zaragoza hasta Tarragona. Desde aquí sube hasta Gerona por Barcelona para descender luego por el arco mediterráneo hasta Málaga, incluidos los dos archipiélagos, con Madrid en el centro como en el "sueño de José». Es la España que "crece», según Alcaide $(1988,67)$, frente a la España en "crisis" (Asturias, Cantabria, Guipúzcoa y Vizcaya), a la que "sobrevive" (Galicia, región del Duero -Burgos, León, Palencia, Valladolid y Zamora-, Subpirenaica - Huesca y Lérida-, y Bética - Cádiz, Córdoba, Huelva, Jaén y Sevilla-) y a la que se "despuebla" (Extremadura, Macizo Ibérico - Cuenca, Guadalajara, Soria y Teruel-, Carpetania - Ávila, Salamanca y Segovia - y La Mancha -Albacete, Ciudad Real y Toledo-).

\section{G) Política de reconversión industrial}

La reconversión industrial llega auspiciada por el poder público y tiene un marcado carácter sectorial con efectos espaciales, aunque éstos nunca fueron tenidos en cuenta de forma prioritaria. Debido, pues, a la concentración espacial de la industria, también las cuantiosas inversiones (1,2 billones), tanto públicas (75 por 100) como privadas (25 por 100), fueron a parar a unas pocas regiones, incidiendo con ello en los desequilibrios territoriales del futuro.

El citado proceso se inicia tardiamente (1983) con respecto a los paises de la CEE (1974) y se concentra en las grandes empresas, olvidándose de las medianas y pequeñas (PYMES), abandonadas a sus propios recursos, que han demostrado su eficacia en el mantenimiento del empleo y su capacidad de adaptación en los tiempos de crisis. 
Para finalizar esta parte sobre la incidencia de la crisis en el tejido socioeconómico español hay que decir que se han producido importantes alteraciones regionales y cambios en su situación económica con «relación a las tendencias que se venían manteniendo desde decenios anteriores» (Mancha, 1984, 49).

En esta coyuntura se han visto menos afectadas las regiones con un grado medio de industrialización y con una agricultura desarrollada. Sin embargo, aquellas que tenían una fuerte especialización industrial (metálicas básicas y transformados metálicos) han sufrido un grave deterioro (Guipúzcoa, Vizcaya, Asturias, Cantabria y Barcelona, en parte).

\section{LA RECUPERACIÓN (1986-1989)}

En el cuatrienio que va de 1986 a 1989 , se mantienen e incluso se consolidan las características regionales que definen la etapa anterior. El citado eje de desarrollo, que parte desde Álava, desciende vertebrado por el Ebro y se abre en abanico describiendo un gran arco desde Gerona a Málaga, con Madrid y los archipiélagos incluidos, polariza el dinamismo económico de los 80 . Incluso se va extendiendo por el sur hacia las provincias occidentales andaluzas, del mismo modo que Madrid profundiza su expansión por la Meseta hacia Guadalajara y Toledo.

Como un ejemplo del azote de los desequilibrios regionales que no cesa, la cornisa cantábrica sigue rebajando su participación en el PIB, aunque Cantabria apunta leves señales de recuperación; las dos Castillas y Extremadura se mantienen en los peldaños más bajos del desarrollo y Galicia, con fuertes desequilibrios intrarregionales, va renovando sus estructuras seculares desde algunos focos dinámicos y emprendedores.

Según Martínez Coriña $(1990,86-88)$ éstas son las causas que explican el desplazamiento del desarrollo económico hacia el Valle del Ebro y el arco mediterráneo:

- "La competitividad y complementariedad" de nuestra agricultura mediterránea en los mercados europeos donde puede ser etiquetada como la California de Europa.

- "La crisis del sector pesquero", agudizada desde nuestro ingreso en la $C E E$, que ha abierto una vía de agua en las provincias atlánticas.

- "La crisis industrial», enconada con las industrias básicas y transformadoras de los metales, que se ha cebado especialmente en la cornisa cantábrica y algunas provincias del interior. 
- «El turismo", principal dinamizador de los servicios y de la construcción, de tanta capacidad de arrastre cuando ésta se pone en movimiento.

- La llegada de grandes masas de "capital extranjero" hacia sectores industriales punta e inmobiliarios. No en vano se ha dicho, por quien puede y sabe, que España es el país donde con más facilidad se gana dinero últimamente.

- El impulso de grandes "obras de infraestructura viaria" desde Madrid hacia el Noreste, Sur-Suroeste y Costa Mediterránea.

- Los «proyectos del 92" que incluyen los Juegos Olímpicos en Barcelona, la Exposición Universal en Sevilla y la capitalidad cultural europea en Madrid: una elección "bingo" con los vientos de desarrollo dominantes a favor.

Con estas causas no agotamos el repertorio de las que inciden en el dinamismo periférico o, visto desde el ángulo contrario, de las que aceleran los desequilibrios regionales. Podríamos insinuar: la polarización de las inversiones, la desigualdad en el reparto de las competencias autonómicas, la falta de una planificación del desarrollo territorial, del sectorial y del macroeconómico, la no incentivación de los procesos industriales no contaminantes y el olvido de las regiones atrasadas al planificar los transportes o la cultura (elección alternativa de Salamanca por Madrid en el 92). Aún podriamos añadir el que se hiciera un reparto más equitativo del Fondo de Compensación Interterritorial: no se valora adecuadamente la participación de las zonas deprimidas en cuanto a espacios de ocio, reservas naturales, materias primas o acogida (imposición) de desechos industriales.

\section{SITUACIÓN ACTUAL DE LOS DESEQUILIBRIOS REGIONALES}

Este artículo podria haber finalizado en el apartado anterior, porque las líneas siguientes corren el riesgo de repetir algunas ideas esparcidas con anterioridad $y$, sobre todo, caer en simplificaciones de una realidad muy compleja. Pero estas páginas han surgido como un producto para la exportación y lo que aquí puede parecer un racimo de obviedades, en el extranjero (Ponencia presentada en el Seminario sobre "Desequilibrios regionales en España y Hungría" realizado entre el Dpto. de Geografía de la UNED y el Instituto de Estudios Regionales de la Academia de 
Ciencias de Hungría, verano de 1990) han de leerse con agradecimiento por su misma simplificación. Espero.

La secretaría de Estado de Hacienda acaba de publicar (1988) un Informe sobre la situación y perspectivas de aquellas regiones que la CEE incluye en su Programa de Desarrollo Regional (PDR). Aunque el conjunto, y cada una de las CCAA, tiene un PIB por habitante inferior a la media comunitaria, el PDR sólo contempla aquellas zonas cuyo producto por habitante queda por debajo del 75 por 100 europeo.

Sin embargo, con el fin de que el panorama sea completo, voy a ampliar el análisis a todas las CCAA, destacando brevemente sus desequilibrios más característicos.

\section{Andalucía}

- Tiene las mayores tasas de paro del país y su volumen representa el 24 por 100 del mismo. Las causas hay que buscarlas en la crisis agrícola y en la estructura de la propiedad que genera un abundante desempleo no absorbido por la debilidad del entramado industrial.

- El sector terciario tiene un peso excesivo, justamente como una compensación anómala del estado de los sectores primario y secundario.

- La cualificación laboral es insuficiente; la diversificación productiva, escasa; la dependencia comercial y técnica, grande y sus estructuras comerciales, deficientes.

- El territorio tiene un articulación débil y padece una grave dependencia energética.

- Existen profundos desequilibrios intraterritoriales, destacando la intensa polarización productiva en torno a Cádiz, Málaga y Sevilla.

- Como aspectos positivos, cuenta con un excelente potencial demográfico, buen clima, sol abundante y la inclusión en el eje de desarrollo mediterráneo.

\section{Aragón}

- Los resultados globales de la zona desfiguran la realidad intrarregional, pues Zaragoza acapara más de dos tercios de la producción y del 
empleo totales. Esta provincia forma parte de la España que "crece», en cambio Huesca "sobrevive" y Teruel "se despuebla".

- Los desequilibrios territoriales se reflejan en la población activa agraria (Zaragoza 22,6 por 100; Huesca 47 por 100 y Teruel 60,1 por 100 ), en la rentabilidad de las explotaciones, en el entramado urbano que carece de ciudades medias y en la concentración de la industria y de los servicios en Zaragoza.

- Las comunicaciones Norte-Sur son insuficientes, pero se beneficia de los flujos que van del Cantábrico al Mediterráneo y desde Cataluña hacia Madrid.

\section{Asturias}

- Existen dos zonas claramente diferenciadas: una «rural» al oeste $y$ al este, cuya actividad no está bien insertada en una economía de mercado, pues su rentabilidad se halla por debajo de la media nacional y ocupa a un 22 por 100 de la población activa, y otra "industrial» especializada en la minería del carbón y en la siderurgia, bocado predilecto para la crisis de los años 70 . Estas industrias están aún en trance de reconversión, han deteriorado el medio ambiente a niveles deplorables y carecen de subsectores diversificados y complementarios.

- Las infraestructuras viarias padecen de extrangulamientos importantes y el turismo, rey Midas de nuestra economía, casi no ha sentado sus reales en estas tierras.

\section{Baleares}

- Apenas iniciado el desarrollo en los años 60, las Baleares fueron consideradas por el turismo internacional como una nueva Arcadia mediterránea. Todas las actividades giran en su rededor. Como resultado, el Producto Interior Bruto (PIB) de 1985 se reparte asi por sectores: Agricultura, 2,6 por 100; Industria, 7,6 por 100 y Servicios 89,8 por 100 .

- Tiene algunos problemas de tráfico aéreo por congestión y varias zonas, de carácter rural, no se benefician del maná turístico que, paulatinamente, se hace más estacional acortando su estancia. La red viaria es insuficiente, también los transportes marítimos y la escasez de agua puede significar un estrangulamiento económico considerable a medio plazo. 


\section{Canarias}

- La economía se polariza hacia los servicios, la industria presenta una dimensión reducida y la agricultura está poco diversificada, sufriendo escasez de suelo y de agua.

- El paro afecta al 24,1 por 100 de la población activa.

- Los desequilibrios más destacables son: escasa cualificación obrera, costes adicionales de transporte por su lejanía de la Península, carencia de recursos energéticos, fragmentación del territorio y dicotomía entre las islas orientales y las occidentales, mucho más desarrolladas éstas que aquéllas.

\section{Cantabria}

- La población aparece muy dispersa, casi 1.000 núcleos, lo que redunda en una deficiente infraestructura de servicios (carreteras, electricidad, alcantarillado, etc.).

- Está catalogada como una región industrial en declive, donde la crisis ha incidido de manera especial en su sector secundario. Sin embargo, aunque participa del retroceso general en que vive la cornisa cantábrica, su deterioro no es tan acusado.

- Hay un fuerte contraste entre las áreas industriales y las dedicadas a la agricultura, que en 1985 aún ocupaba el 23 por 100 del empleo, con un subsector maderero sobredimensionado y poco productivo.

- Todavía presenta una ligera especialización industrial y el desarrollo de sus servicios está por debajo de la media del país.

\section{Castilla-La Mancha}

- Dentro de la España que se «despuebla», la Comunidad de Castilla-La Mancha tiene una población muy envejecida y una densidad muy baja $\left(21 \mathrm{hab} / \mathrm{km}^{2}\right)$, que todavía no ha tocado fondo. Su agricultura, que acapara el 27,5 por $100 \mathrm{del}$ empleo, mantiene características tradicionales y está escasamente integrada con la industria agroalimentaria.

- La industria se polariza en los subsectores químico, energético y minerales no metálicos. El resto se compone de empresas muy pequeñas, artesanales, sin capacidad de renovación tecnológica. 
- Adolece de infraestructuras adecuadas en transporte, sanidad y educación y la vivienda, en general, es antigua y está mal acondicionada.

- Posee una red urbana poco organizada por falta de ciudades intermedias.

\section{Castilla y León}

- Como en la región anterior, la baja densidad y el envejecimiento de la población caracterizan estas tierras, donde el 93 por 100 de los municipios tiene menos de 2.000 habitantes y las ciudades intermedias apenas existen.

- El paro es inferior (16,3 por 100) a la media nacional (19,5 por $100)$ en 1987 por sus especiales condiciones económicas: predominio de una agricultura tradicional (27 por 100 de la población activa), con explotaciones de reducido tamaño, y apenas integrada en los grandes circuitos comerciales.

- La industria se concentra en unos pocos núcleos especializados como Valladolid, Burgos, Miranda de Ebro, etc.

- La infraestructura viaria es insuficiente y los servicios se hallan muy por debajo de la media nacional.

\section{Cataluña}

- En el 6,3 por 100 del territorio catalán vive el 12,8 por 100 de la población española y el 16,4 por 100 de la activa (1985). Por su especialización industrial (textil) la crisis económica le afectó sobremanera, aunque ha recibido fuertes inversiones durante la reconversión posterior.

- Los principales desequilibrios se deben a la escasez de energía y de recursos hídricos, así como a la falta de infraestructuras viarias, de suelo industrial en la corona media barcelonesa y a la mínima inversión para conseguir tecnología propia de cara al futuro.

- En el interior hay numerosas comarcas en declive agrícola 0 industrial (industrias textiles tradicionales y transformadoras de los metales) y la costa, junto con el área metropolitana, aparece muy congestionada. 


\section{Comunidad Valenciana}

- Esta región se halla dentro de la zona estratégica del desarrollo, pero sufre algunos desequilibrios importantes. El primero de ellos, la excesiva concentración de sus gentes en la franja costera y especialmente en el área metropolitana de Valencia y en los núcleos de Alicante-Elche, Gandía y Castellón. Hacia el interior, parte de los secanos intermedios y la montaña adolecen de infraestructuras viarias y poco a poco se van despoblando.

- A medio plazo va a sufrir un fuerte estrangulamiento en el desarrollo por la situación de los recursos naturales y del medio ambiente: intensa orosión del suelo, deforestación por incendios y contaminación de las aguas superficiales y de los acuiferos.

- El equipamiento social es insuficiente, sobre todo en los transportes, salud pública y universidad; produce un 5 por 100 de la energía que consume.

\section{Extremadura}

- Por varios conceptos se sitúa entre las regiones más desfavorecidas: tiene una densidad de $25 \mathrm{hab} / \mathrm{km}^{2}$, una tasa de actividad de tres puntos por debajo de la media y un paro de seis por encima de la misma. La renta "per capita" es la más baja, tan sólo un 47 por 100 de la que disfruta Madrid o Baleares.

- Se repiten aquí todos los desequilibrios apuntados con anterioridad: población envejecida, deficiencias infraestructurales profundas, agricultura tradicional, industria minifundista y poco competitiva, baja productividad general y un sistema urbano mínimamente integrados.

\section{Galicia}

- Forma parte de la España que "sobrevive». De tradición emigrante y agraria, más del 40 por 100 de la población activa está vinculada al sector primario, con una agricultura familiar y minifundista.

- La industria aparece muy concentrada en La Coruña -FerrolVigo y Pontevedra, dejando grandes espacios vacíos de su presencia. Está muy especializada en derivados de pesca y construcción naval, subsectores con graves problemas de reestructuración. 
- La economía aparece fuertemente desarticulada debido, entre otras deficiencias, al estado de las infraestructuras viarias y de los servicios en general.

\section{Madrid}

- Padece una total dependencia energética, pues produce 20 veces menos de lo que consume.

- Otros graves desequilibrios son: la contaminación ambiental, la escasez de servicios sanitarios públicos $(3,2$ médicos por 10.000 habitantes frente a la media nacional de 23,1 ), el dualismo social (grandes fortunas y cada vez mayores bolsas de pobreza), el deterioro de las condiciones sociolaborales por el crecimiento de la economía sumergida, de la venta ambulante, etc., y la especulación inmobiliaria.

- La Sierra Norte, agraria y con una población envejecida, se despuebla año tras año y la capital es una ciudad "cautiva" cuya infraestructura viaria encarece los costos, retrasa cualquier tipo de comunicación interior y hierve en un entorno poblacionalmente desértico.

\section{Murcia}

- Se halla ubicada dentro del arco mediterráneo que "crece", pero aún presenta algunos desequilibrios. El sector agrario se mueve entre explotaciones minifundistas y poco tecnificadas y adolece de falta de recursos hídricos y de una comercialización organizada.

- El sector industrial hace acto de presente exclusiva en la ciudad y en la Vega del Segura y los servicios son insuficientes no sólo para la demanda presente sino sobre todo para la que se prevé.

- Otras deficiencias son el estado de sus comunicaciones, el deterioro medioambiental y el bajo nivel de formación empresarial y obrera.

\section{Navarra}

- Situada en el eje del Ebro, se beneficia del gran desarrollo de la zona, aunque presenta algunas graves deficiencias como el dualismo regional entre el noroeste agrícola y el resto, fuertemente industrializado. 
- La crisis de los 70 se cebó en la fabricación de electrodomésticos de línea blanca y en el papel, pero aún mantiene una especialización industrial alta.

- El desempleo está dos puntos por debajo de la media nacional, sin embargo los senvicios presentan un débil desarrollo con una participación en el VAB del 51,9 por 100 frente al 61,5 por 100 nacional (1985).

\section{País Vasco}

- Hay que distinguir entre la zona litorial (Guipúzcoa y Vizcaya) y el interior (Álava): aquél, en profunda crisis desde hace casi dos décadas $y$ éste, incluido en el eje del Ebro.

- Ha dejado de ser tierra de inmigrantes, cambiando de signo en la actualidad, aunque mantiene una gran densidad demográfica.

- La participación del sector primario en el VAB es muy reducida (2 por 100), así como la población activa ocupada $(5,5$ por 100$)$.

- Su especialización en la siderurgia, naval y transformados metálicos ha sido el mejor caldo de cultivo para la crisis industrial que ha originado un paro varios puntos por encima de la media nacional.

- Mantiene una fuerte especialización industrial (1,493 sobre 1,000 ), pero sus servicios se hallan muy por debajo del nivel medio. En el deterioro socioeconómico ha influido la inseguridad creada por el terrorismo etarra.

\section{La Rioja}

- Ubicada en el valle del Ebro, forma parte de las regiones que crecen y se ha incorporado con cierto retraso al desarrollo industrial, al beneficiarse, detrás de Álava y Navarra, del rebose económico del País Vasco.

- El desequilibrio regional ofrece en esta Comunidad Autónoma un ejemplo de libro: por una parte, el valle donde las actividades y la población se apiñan a lo largo del eje del Ebro y por otra, la zona serrana, un desierto demográfico que rebasa las cumbres cameranas y se extiende por las tierras de Soria.

- El dinamismo riojano se nutre de la especialización agrícola que enlaza con la industria agroalimentaria. 
- Presenta, sin embargo, una infraestructura sanitaria, turística y universitaria muy débiles.

\section{CONCLUSIONES}

a) En una economía de mercado, competitiva, los desequilibrios entre las distintas regiones son inevitables. En el caso de España, el fenómeno tiene un pedigri multisecular, aunque en la Edad Moderna era el centro de la Península, y no la periferia, el que concentraba los mejores recursos humanos y económicos.

b) Las desigualdades pueden analizarse desde muchos puntos de vista, pero la densidad demográfica, la productividad y el nivel de empleo y de paro son quizá los criterios más contundentes para medirlas.

c) Hasta los años 50 el país vive y camina a paso de flagelante, apartado del ágora europea. Al abandonar la autarquía, su ritmo de crecimiento es considerado como "milagroso", aunque el proceso se "humaniza" si tenemos en cuenta el pobre bagaje con que inicia la marcha (1960-1973). La población se desplaza masivamente a la periferia, la industria llama a la industria y los desequilibrios se agudizan.

d) La crisis económica generalizada de los 70 se inicia entre nosotros con cierto retraso por la transición política y dura hasta 1985. Se detienen los movimientos migratorios e incluso van regresando los emigrantes europeos de la etapa anterior. Se hunden innumerables empresas levantadas sobre la arena del alborozo desarrollista y el paro, como una resaca, llega a sobrepasar el 22 por 100 de la población activa como media nacional. En algunas regiones, este procentaje hubiera parecido una bendición: Andalucía (31,3 por 100), Extremadura (28,1 por 100) y Canarias $(26,4$ por 100$)$ en 1986.

e) Desde 1986 hay una ligera recuperación que beneficia a grupos minoritarios. Sin embargo, el desempleo persiste con una media muy superior a la europea. El desarrollo se extiende, en forma de $Y$, por el valle del Ebro, arco mediterráneo hasta Málaga, archipiélagos y Madrid.

f) La política de desarrollo regional, que nunca ha existido como tal, va tomando cuerpo tímidamente y de forma fragmentada a través de los gobiernos autonómicos. 


\section{BIBLIOGRAFIA}

ALACAIDE INCHAUSTI, J., 1984: «Evolución de la renta regional en los años de crisis económica (1973 a 1981)", ICE, n. ${ }^{\circ}$ 609. Madrid, págs. 921.

- 1988: "Las cuatro Españas económicas y la solidaridad regional», Papeles de la Economia Española, $\mathrm{n}^{\circ}$ 34. Madrid, págs. 62-81.

Alonso FeRnÁndeZ, J., 1990: La nueva situación regional. Madrid, Ed. Síntesis, 166 págs.

Álvarez Llano, R., 1986: «Evolución de la estructura económica regional de España en la historia: una aproximación», Situación, n. ${ }^{\circ}$ 1. Madrid, págs. 5-61.

BANCO BILBAO. Varios años: Renta Nacional de España y su distribución provincial.

Bielza de Ory, V. y Galindo, M. ${ }^{a}$ C., 1985: "La génesis de los desequilibrios regionales españoles y las nuevas estrategias ante la crisis económica y la CEE", Regional Conference on Mediterranean Countries. Zaragoza, Ed. Univ. de Zaragoza, pág. 255-271.

CASAS TORRES, J. M. et alii., 1968: "Algunos aspectos de los desequilibrios regionales españoles en 1967", XXI Congreso Internacional de Geografia. India. Madrid, CSIC, págs. 31-65.

Cuadrado Roura, J. R., 1988: «Tendencias económico-regionales antes y después de la crisis en España», Papeles de Economia Española, n. ${ }^{\circ}$ 34. Madrid, págs. 17-60.

GiRALDE NúÑEz, M. ${ }^{\text {a }}$ T. y COMEZ, T., 1988: «Empleo y paro a nivel regional: 1976-1986", Papeles de Economía Española, n. ${ }^{\circ}$ 34. Madrid, págs. 267-298.

Higueras Arnal, A., 1980: "Los desequilibrios regionales en España", La Región y la geografia española, AGE. Valladolid, págs. 227-241.

Mancha Navarro, T., 1984: "Perfil industrial de las regiones españolas", ICE, n. ${ }^{\circ}$ 609. Madrid, págs. 37-56. 
martínez Cortiña, R., 1990: La transición económica de España. Madrid. Ed. Ciencias Sociales, 282 págs.

MÉNDEZ GUtIÉRREZ, R., 1990: “Las actividades industriales" en Bosque, J. (dir.) Geografía de España, II. Barcelona, Ed. Planeta, págs. 73230.

MINISTERIO DE ECONOMÍA Y HACIENDA, 1987: Plan de desarrollo regional. España, 1986-1990. Madrid (Mimeo), 4 vols.

- 1989: Programa de desarrollo regional de España. 1989-1993. Madrid, 326 págs.

PAPELES DE ECONOMIA ESPAÑOLA, 1988: Desarrollo regional en los siglos $x I x$ y $x x$ (Anexo. 2), n. ${ }^{\circ} 34$. Madrid.

Racionero, L., 1987: España en Europa. Barcelona, Ed. Planeta, 213 págs.

VAzQUez BARQUero, A., 1984: «Desarrollo con iniciativas locales en España", ICE, n. ${ }^{\circ}$ 609. Madrid, págs. 57-68.

- 1986: "El cambio del modelo de desarrollo regional y los nuevos procesos de difusión en España", Estudios Territoriales, n. ${ }^{\circ} 20$. Madrid, págs. 87-110. 